\title{
RELATIONSHIP BETWEEN JOB DEMANDS AND PSYCHOLOGICAL OUTCOMES AMONG NURSES: DOES SKILL DISCRETION MATTER?
}

\author{
SARA VIOTTI and DANIELA CONVERSO \\ University of Turin, Turin, Italy \\ Department of Psychology
}

\begin{abstract}
Objectives: The aim of the present study was to assess both the direct and indirect effects (i.e., interacting with various job demands) of skill discretion on various psychological outcomes (i.e., emotional exhaustion, intention to leave, affective well-being, and job satisfaction). Material and Methods: Data were collected by a self-reported questionnaire in 3 hospitals in Italy. The sample consisted of 522 nurses. Moderated hierarchical regression analyses were employed. Results: The findings highlighted the direct effect of skill discretion on reducing emotional exhaustion, intention to leave, sustaining affective well-being and job satisfaction. As regards interaction effect, the analyses indicated that skill discretion moderates the negative effect of disproportionate patient expectations on all the considered psychological outcomes. On the other hand, skill discretion was found to moderate the effect of cognitive demands on turnover intention as well as the effect of quantitative demands on emotional exhaustion and job satisfaction only in conditions of low job demands. Conclusions: The study revealed some interesting findings, suggesting that skill discretion is not a resource in the pure sense, but that it also has some characteristics of a job demand. The study has relevant practical implications. Particularly, from a job design point of view, the present study suggests that job demands and skill discretion should be balanced carefully in order to sustain job well-being and worker retention.
\end{abstract}

Key words:

Job satisfaction, Job demands, Skill discretion, Emotional exhaustion, Intention to leave the profession,

Well-being at work

\section{INTRODUCTION}

Although in the occupational health psychology (OHP) literature skill discretion is considered a crucial dimension, its role in stress and motivational processes in the workplace is not entirely understood. Skill discretion refers to a person's opportunity to acquire and use specific job skills in the work process [1]. In the Job Demand-Control (DCS) model, Karasek [1] assumes that together with decision authority, skill discretion is a job resource that enables workers to keep control of their jobs, helps workers cope with job demands and thus, contributes to sustaining job well-being and reduction of stress. In a similar vein, the Job DemandResources (JD-R) model [2,3] includes skill discretion among job resources that are defined as those aspects of work environment that help achieve work goals and reduce job demands and the associated psychological costs.

These 2 models entail 2 main ways in which workers' job behavior and psychological health are affected by

The study was partially founded by Gloria Foundation (Italy) with the project "Lessening malaise and promoting well-being in the healthcare sector" ("Contrasto del disagio e promozione del benessere lavorativo in Sanità") (R.O.L. 2624/2011).

Received: November 24, 2014. Accepted: June 26, 2015.

Corresponding author: S. Viotti, University of Turin, Department of Psychology, via Verdi 8, 10124 Turin, Italy (e-mail: sara.viotti@unito.it). 
job resources [4-6]. The 1st way is direct (or additive). It is described by a motivational process that assumes that job resources have motivational potential and lead to high job well-being. The 2nd way is described as an indirect effect and concerns interaction with job demands in influencing workers' well-being. A buffering hypothesis, the one that assumes that job resources buffer the impact of job demands on workers' well-being, implies this kind of relationship. More specifically, in the buffer hypothesis, in order to counteract strain, job resources should be increased, whereas demands do not have to [4].

In the case of several job resources, for example social support [7-9] and job autonomy [9,10], there is some evidence that supports these assumptions. However, evidence concerning skill discretion is less consistent, especially with regard to the buffering hypothesis. As argued by some scholars [10,11], skill discretion is controversial because it may not work tout-court as a resource but can also share some features with job demands.

Skill discretion refers not only to the opportunity to use consolidated skills but also to the process of learning new things and of exercising creativity. These 2 aspects, although can be considered as positive characteristics of the job, require mobilization of energy related to the learning process. In that sense, skill discretion could have a different nature from the other commonly considered resources, e.g., job autonomy and social support, that work fully as a support and do not require depletion of energy. This is also suggested by a considerable number of studies that have reported a positive relationship between skill discretion and job demands [e.g., 6,11,12].

Despite plausibility of this argument, no studies have paid specific attention to understanding the real nature of skill discretion, and in particular whether and under what conditions it may also operate as a kind of job demand, e.g., exacerbating rather than buffering detrimental effect of job demands on workers.

Thus far, the studies focusing specifically on skill discretion were mainly oriented towards testing whether skill discretion satisfies the principles underlying the assumption of motivational and/or buffering processes or not $[4,5]$. In addition, lack of understanding of the real nature of skill discretion may be attributed to the fact that most studies have not considered skill discretion and decision authority separately, but used them together to define job control. According to de Jonge et al. [10], this practice could fail to recognize specific effects of the 2 sub-dimensions. Also, different types of job demands were rarely considered separately (e.g., emotional, cognitive, workload, etc.), not allowing the research to highlight differences concerning how skill discretion works in combination with various job demands.

In the light of these considerations, the present paper should contribute to filling this gap. The research is intended to examine both direct and indirect effects of skill discretion, considering various job demands (i.e., disproportionate patient expectations, quantitative demands, cognitive demands) on various psychological outcomes (i.e., on emotional exhaustion, affective well-being, job satisfaction, and intention to leave).

\section{Job demands in nursing profession}

Literature has largely highlighted the fact that nursing is a stressful profession [13-17]. Reasons for this include constant involvement in highly emotionally demanding relationships with care-recipients as well as exposure to high cognitive and quantitative demands.

In recent times, in Italy as well as in many Organization for Economic Co-operation and Development (OECD) countries, many new factors responsible for further intensification of nursing job demands have emerged.

Shortage of resources in the health sector combined with an increased proportion of the elderly in the population 
have caused more quantitative demands on nurses, especially in terms of workload and a more hectic pace $[18,19]$. Therefore, nurses, more and more often have to deal with the requirement to "do more with less" [20]. This scenario may also exacerbate the demanding nature of the relationships with care-recipients. In particular, nurses even more frequently may have to manage negative feedback and claims from patients and their relatives because the provided service does not meet their expectations. This, however, may be disproportionate considering the resources of the organizational system [18]. Considering that the literature highlights the relevance of demands of a relational, cognitive, and quantitative nature for nurses [21], the present study chooses to take these into account.

Among relational demands, disproportionate expectations was considered. According to Dormann and Zapf [22], disproportionate expectations refer to patients' or relatives' attitudes and behaviors in demanding what is considered unreasonable and unacceptable from the service providers' point of view. Quantitative demands, on the other hand, refer to work overload or work pressure or how fast workers are required to perform their job tasks [23]. Cognitive demands refer to the extent to which the tasks require workers to expend sustained mental effort in carrying out their duties [23].

\section{Psychological outcomes as dependent variables}

In order to extensively investigate whether and how the interaction between skill discretion and job demands affects workers' health and attitude towards the job, the present study takes into consideration a quite wide range of psychological outcomes: emotional exhaustion, affective well-being at work, job satisfaction and intention to leave the profession.

Emotional exhaustion is considered as a core dimension of burnout [24], and can be defined as a psychological response to chronic work-related stress of an interpersonal and emotional nature that appears in professionals working directly with clients, patients or other recipients $[25,26]$. Intention to leave is considered as the most accurate predictor of behavioral turnover, generally defined as "voluntarily leaving" the job or organization [27,28]. For hospitals, when nurses leave, there are several negative results. There is loss of the tacit knowledge required to ensure a safe and effective care of patients plus training and recruitment costs to replace them with new resources [20,29].

Affective well-being refers to a person's overall emotional experience at work that reflects a person's self-described happiness [30-32]. According to Danna and Griffin [33], the concept of happiness denotes a preponderance of positive affects (e.g., being energetic, excited and enthusiastic), over negative affects (e.g., anger, disgust, guilt and depression).

Job satisfaction is generally defined as an employee's affective reaction to a job, which comprises evaluation of the degree to which the job meets the worker's needs. It can be considered as a global feeling about the job or as a related constellation of attitudes towards various facets of the job [34]. Global approach is used when the overall attitude is taken into account, while the facet approach is used to explore which elements of the job produce satisfaction or dissatisfaction [35].

\section{Theoretical framework}

The present study refers to the Conservation of Resources (COR) [36,37] theory as a framework for reading mechanism underlying the relationship between job demands, job resources and workers' outcomes. Conservation of Resources is a motivational theory based on the idea that individuals strive to obtain, retain, foster and protect resources. Primary resources are those related to basic and survival aspects. Examples include: health, shelter and basic social needs. People may instinctively seek such primary resources [37]. On the contrary, secondary resources 
are culturally definite and may aid in gaining or protecting peoples' primary resources.

According to Hobfoll $[36,37]$, the COR theory is based on 3 fundamental principles:

1. Resource loss is disproportionately more salient than resource gain, which means that real or anticipated resource loss has stronger motivational power than the expected resource gain.

2. People must invest resources in order to protect against resource loss, recover from loss and gain resources.

3. Those with greater resources are less vulnerable to resource loss and more capable of orchestrating resource gain; conversely, those with fewer resources are more vulnerable to resource loss and less capable of resource gain.

As regards the workplace, job demands are generally perceived as loss because meeting such demands requires investment of valued resources, viewed as gains [38]. According to this, job demands may activate a loss cycle leading to several consequences on workers in the short, medium, and long term. In the short term, job demands may determine a reduction of affective well-being due to, e.g., fear of loss of the previously gained resources.

This can also result in feelings of exhaustion and fatigue due to investment of an excessive amount of psychological and physiological energy. In the medium term, job demands may affect job satisfaction that refers to an effective and cognitive evaluation of the job. For example, being exposed to a job demand such as disproportionate expectations from patients may lead workers to feel unsatisfied because of the impossibility of establishing good relationships with such patients and of meeting their expectations. In the long term, excessive job demands may also lead to actively seeking strategies to modify a situation in which personal resources are in jeopardy. For example, excessive work load may lead workers to develop thoughts of leaving the job because it makes it impossible to devote enough time to the family.
In this context, it may be interesting to understand the role of skill discretion and, in particular, whether and how it affects psychological outcomes in the interaction with job demands. According to the COR theory, skill discretion is a secondary resource and may be useful in maintaining and gaining new resources.

From a general point of view, opportunity to exercise skill discretion may sustain positive emotional feelings of the workers and job satisfaction by fostering individual's needs for self-actualization and self-realization through the work [39]. However, since skill discretion may also require mobilization of energy due to the effort, e.g., in order to learn new things, it is plausible that, in some circumstances, it may exacerbate, rather than buffer, the relationship between job demands and psychological outcomes. A typical example of an action that describes skill discretion in the nursing context is acquiring information about the patients' health condition and connecting it with the previously acquired nursing knowledge.

Those may be per se aspects of the job that sustain motivation and well-being because they foster development of competence. However, when those actions are needed for responding to a cognitive demand such as making a decision about a patient in a critical health condition, skill discretion may be perceived by the workers as a kind of additional demand. In that sense, in accordance with the COR theory [36,37], skill discretion may contribute to the process of depletion of energy, altering psychological well-being of workers, and also, under chronic conditions, leading workers to desire to leave their job.

\section{Relationship of job demands}

\section{with emotional exhaustion, intention to leave, job satisfaction and affective well-being}

In the present paper, while studying direct and indirect effects of skill discretion, the relationships between 3 job demands and the outcomes were also verified. 
From an empirical point of view, the literature extensively demonstrates a strong, direct and positive relationship between the 3 demands considered in this study and emotional exhaustion.

Dormann and Zapf [22] have shown that disproportionate customer expectations led to emotional exhaustion in samples of employees in various service occupations in Germany. Viotti et al. [40] have found the same significant relationship in a sample of Italian health-care workers. The literature also indicates that quantitative demands are a strong predictor of emotional exhaustion. Lee and Ashforth [41], in a meta-analysis on 56 independent samples from various occupational sectors, have found quantitative demands to be correlated with emotional exhaustion. In a similar vein, the studies of van Daalen et al. [42] and Greenglass et al. [43] have highlighted this relationship among large health-care samples. There is also empirical evidence that also cognitive demands increase emotional exhaustion [44-46].

The literature identifies job demands as one of the stronger predictors of intention to leave [47]. In a study examining nursing turnover from a generational perspective, nearly half of the nurses in each of 3 generations considered identified high quantitative and relationship demands as the main reasons to consider leaving their jobs [48]. Similarly, Li et al. [49], in a sample of 1521 nurses, have found that emotional demands and quantitative demands were associated with an intention to leave measured both at the baseline level and 1 year later.

Quite a large number of studies demonstrate the link between job demands with both job satisfaction and affective well-being $[4,5,11]$. This is especially true for quantitative demands. However, cognitive demands are also considered predictors of these outcomes. The relationship with relational demands, such as disproportionate patient expectations, is less investigated. However, it is plausible to hypothesize that the perception that the service provided does not meet expectations of the patient may reduce satisfaction and well-being for several reasons. For example, negative feedback about the service can diminish workers' satisfaction. Similarly, having to deal with adverse patients may determine a decreased level of affective well-being. Based on these findings, all the 3 job demands are expected to be positively related to emotional exhaustion and intention to leave, and negatively to job satisfaction and emotional well-being (hypothesis 1- H1).

\section{Direct and indirect effects of skill discretion}

Skill discretion is a work characteristic that fosters individual's needs for self-actualization and self-realization through the work [39]. In addition, the present paper argues that skill discretion works as a resource tout-court, suggesting that it could share some features with job demands, because learning process may require depletion of some energy.

As regards the direct effect, many studies provide evidence that skill discretion is negatively associated with emotional exhaustion and turnover intention, and positively with job satisfaction and affective well-being [4,5,50-52]. However, in some cases, also the opposite has been found. For example, a heterogeneous study by de Jonge et al. among 1739 employees has shown that skill discretion was positively associated with psychosomatic health complaints and sickness absence [53]. Since according to the Conservation of Resources theory [36,37], both directions of the association are plausible, in the present study the following conflicting hypotheses were formulated:

- $\mathrm{H} 2 \mathrm{a}$ - skill discretion is negatively associated with emotional exhaustion and intention to leave, and positively with affective well-being and job satisfaction;

- H2b - skill discretion is positively associated with emotional exhaustion and intention to leave, and negatively with affective well-being and job satisfaction.

The buffering hypothesis suggests that skill discretion as a job resource moderates the positive relationship of job demands with emotional exhaustion and intention to leave 
as well as the negative relationship of job demands with job satisfaction and affective well-being [36,37,54]. Specifically, since, according to the COR theory [36,37], job resources have a motivational potential, the following expectations about skill discretion, consistent with the buffering hypothesis, can be formulated:

- H3a - the relationship between job demands (i.e., disproportionate expectations, quantitative demands, and cognitive demands) and the outcomes (i.e., emotional exhaustion (positive) and intention to leave (positive), affective well-being (negative), and job satisfaction (negative)) is stronger in conditions of low skill discretion and weaker in conditions of high skill discretion.

In addition, higher levels of emotional exhaustion and intention to leave, and lower levels of affective well-being and job satisfaction will be found among those with low skill discretion.

However, the literature does not always support these assumptions [4-6,54]. Actually, besides the buffering hypothesis, the contrary is also plausible: skill discretion, combined with job demands, may exacerbate job demands and contribute to depletion of energy. This is also consistent with one of the principles of the COR theory, which states that resource loss is disproportionately more salient than resource gain $[36,37]$. Even though skill discretion implies a gain at the end of the process, the effort of learning new things may require a certain amount of energy. Hence, it is reasonable to hypothesize that skill discretion in interaction with job demands, may exacerbate psychological costs associated with job demands.

Accordingly, the following hypothesis, that has to be seen as alternative to $\mathrm{H} 3 \mathrm{a}$, can be formulated: $\mathrm{H} 3 \mathrm{~b}$ - the relationship between job demands (i.e., disproportionate expectations, quantitative demands and cognitive demands) and the outcomes (i.e., emotional exhaustion (positive) and intention to leave (positive), affective well-being (negative) and job satisfaction (negative)) is weaker in conditions of low skill discretion and stronger in conditions of high skill discretion. Moreover, higher levels of emotional exhaustion and intention to leave, and lower levels of affective well-being and job satisfaction will be found among those with high skill discretion.

\section{MATERIAL AND METHODS}

\section{Participants and procedure}

The study was cross-sectional and not-randomized. Data were collected during a multi-center intervention-research conducted in 3 hospitals in North-Western Italy in 2012. Hospital administrations evaluated, endorsed and authorized the research, allowing researchers to use the data for scientific purposes. Upon approval, department chiefs and nurses coordinators from each ward were asked for authorization to administer the questionnaire to the nurses. An additional ethical approval was not required since there was no treatment, including medical invasive diagnostics or procedures causing psychological or social discomfort for the participants, nor were the patients the subject of data collection. However, the research conforms to the provisions of the Declaration of Helsinki in 1995 (as revised in Edinburgh in 2000) and all ethical guidelines were followed as required for conducting human research, including adherence to the legal requirements of the study country (Italy).

The participants volunteered for the research and were not asked to sign consent forms because the return of the questionnaire implied their consent. The cover sheet clearly explained the research aim, voluntary nature of participation, anonymity of the data and elaboration of the findings.

The sample consisted of 522 nurses. The majority were women $(82.2 \%, \mathrm{~N}=429)$, with the age ranging 22-62 years $($ mean $(\mathrm{M})=36.98$, standard deviation $(\mathrm{SD})=8.53)$. In addition, $56.9 \%$ of them were married or living with partners, $34.7 \%$ were single, $7.3 \%$ were divorced and $40 \%$ were widowed.

The average job seniority in the health sector was 13.72 years $(\mathrm{SD}=9.05)$ and ranged from 1 month 
to 39 years. The research participants were employed in acute $(42.1 \%)$ and non-acute $(57.9 \%)$ care wards.

\section{Measures}

The data were obtained by a self-reported questionnaire including 2 sections. The 1st was dedicated to collecting socio-demographic (gender, age and marital status) and professional (units and years in the health sector) data, which in the present study were used as control variables. The 2nd section included scales aimed at measuring job demands, skill discretion and psychological outcomes. Table 1 reports descriptive statistics (means and standard deviations) and Pearson's correlations for all the sub-scales considered in the study.

\section{Job demands}

Disproportionate patient expectations (DE) were measured by the sub-scale from the customer-related social stressors (CSS) by Dormann and Zapf [22]. The sub-scale consisted of 8 items (e.g., "Our patients' demands are often exorbitant") and reported a Cronbach's $\alpha$ of 0.91 . To measure quantitative (QD) and cognitive (CD) demands, 2 subscales of the Job Content Questionnaire $[55,56]$ were employed. The former (e.g., "I am asked to do an excessive amount of work") included 5 items and showed a Cronbach's $\alpha$ of 0.69. The latter (e.g., "My job requires long periods of intense concentration on the task") was a 4-item scale with an $\alpha$ of 0.67 . Responses on all the above-mentioned sub-scales were given on a 4-point scale with a range between 1 (strongly disagree) and 4 (strongly agree).

\section{Skill discretion}

The subscale included in the Job Content Questionnaire (JCQ) $[55,56]$ was employed. It consisted of 5 items (e.g., "My job requires that I learn new things") and reported a Cronbach's $\alpha$ of 0.82 . Responses were given on a 4-point scale with a range between 1 (strongly disagree) and 4 (strongly agree).

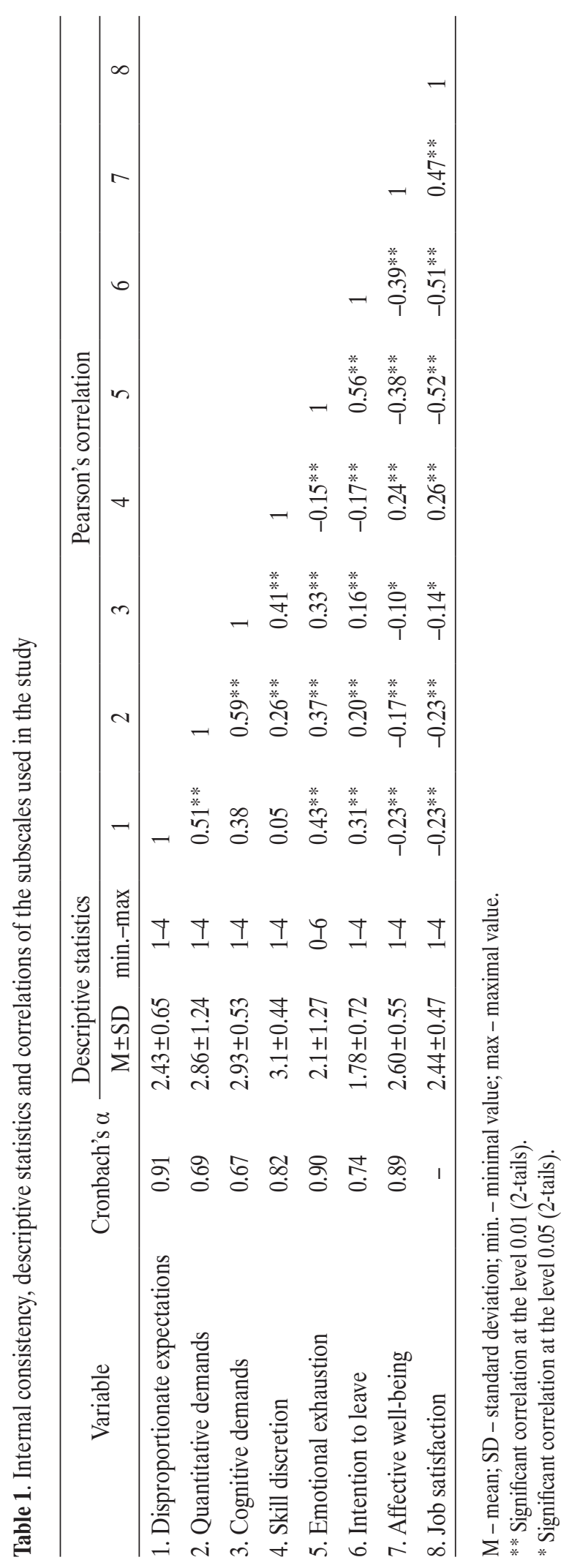




\section{Psychological outcomes}

Emotional exhaustion (EE) was measured using the 9-item sub-scale (e.g., "I feel emotionally drained from my work") from the Italian version of Maslach Burnout Inventory [26,57]. The sub-scale reported a good internal consistency $(\alpha=0.90)$. Responses on the sub-scale were given on a 7-point scale with a range between 0 (never) and 6 (every day).

Intention to leave was measured by a tailor-made scale consisting of 4 items that ask the respondents to indicate how often, in the last 6 months, they thought of leaving their workplace by: looking for a similar job in another organization, asking for a transfer inside the organization, changing the type of a job, or (early) retiring from labor market. Responses on this sub-scale were given on a 4-point scale with a range of 1 (never) and 4 (always). The scale reported a Cronbach's $\alpha$ of 0.71 .

Affective well-being at work (AW) was measured with 13 mood items adapted from Daniels et al. [58]. The participants were asked to indicate how often they have felt, for instance: optimistic or anxious, at work over the past month ( 1 = never, 4 = always $)$. After reversing negative items, as suggested by previous studies [29,58], a global score for affective well-being was computed $(\alpha=0.89)$.

Job satisfaction (JS) was measured by the following singleitem: "Taking everything into consideration, how satisfied do you feel about your job as a whole?". The item was rated on a 4-point scale that ranged between 1 (extremely dissatisfied) and 4 (extremely satisfied) [32,59].

\section{Control variables}

As suggested by the literature, gender $(0=$ male, $1=$ female), age, marital status $(0=$ no living with partner, $1=$ living with partner), job seniority and type of ward $(0=$ non-acute care ward, $1=$ acute care ward $)$ would be potential confounders for emotional exhaustion $[25,60]$, turnover intention [15], affective well-being [61] and job satisfaction [62]. In view of that, they were taken into consideration as controls variables.

\section{Data analyses}

All the analyses were performed using SPSS 21.

In order to examine correlations between the subscales used in the study, Pearson's r, for each pair of scales, was calculated.

The moderated hierarchical regression analyses were employed to examine the main effect of job demands and skill discretion, as well as their interaction effects on emotional exhaustion, intention to leave, affective well-being and job satisfaction. For each moderated hierarchical regression performed, predictor variables were entered within 3 successive steps. In the 1st step, demographical (gender, age and marital status) and occupational (years in the health sector and type of unit) variables were entered as the control variables. In the 2nd step, standardized index of job demands and the skill discretion were entered. In the 3rd step, interaction terms, the product between job demands and skill discretion, were entered.

In the cases in which the interaction term showed a significant value, the simple slope procedure recommended by Aiken and West [63] was adopted in order to further examine the pattern of the relationship.

The risk of multicollinearity between the independent variables was controlled by standardizing all the indexes. Analyses indicated that there were no signs of multicollinearity in any of the carried out regression models. For each independent variable, the tolerance index (1/VIF variance inflation factor) never exceeded the score of 0.82 (cut-off < 0.20) [64].

\section{RESULTS}

\section{Preliminary analyses}

Table 1 reports correlations among the subscales. Skill discretion reported a positive and significant correlation with quantitative $(r=0.26)$ and cognitive $(r=0.41)$ demands, whereas 
the correlation with disproportionate expectations was not significant. All the outcomes were found significantly correlated with the 3 considered job demands and skill discretion in the expected directions. More specifically, emotional exhaustion and intention to leave were found to be positively correlated with all the considered job demands, and negatively with skill discretion. On the other hand, affective wellbeing and job satisfaction showed a positive association with skill discretion, and a negative with job demands.

\section{Moderated regression with emotional exhaustion as a dependent variable}

Table 2 reports the results of the moderated hierarchical regression where emotional exhaustion was entered as a dependent variable.

In the 1st step, entering the control variables did not produce a significant value of $\mathrm{R}^{2}$. In the $2 \mathrm{nd}$ step, when job demands and skill discretion were entered, $\mathrm{R}^{2}$ reached a significant value of 0.319 . Within the control variables, job seniority was significantly and positively associated with the outcome $(\beta=0.20, p=0.04)$. Moreover, in line with $\mathrm{H} 1$, emotional exhaustion was positively correlated with disproportionate expectations $(\beta=0.29, \mathrm{p}=0.00)$, cognitive demands $(\beta=0.16, p=0.01)$ and quantitative demands $(\beta=0.25, p=0.00)$. In line with $\mathrm{H} 2 \mathrm{a}$ (H2b has to be rejected), emotional exhaustion was found negatively correlated with skill discretion $(\beta=-0.24, p=0.00)$.

In the case of the 3 rd step, entering the 3 interactional terms determined a significant increase of the $\mathrm{R}^{2}$ value $\left(\Delta \mathrm{R}^{2}=0.04\right)$. Within the control variables, in addition to job seniority $(\beta=0.19, p=0.05)$, the type of a unit also became significant $(\beta=-0.12, p=0.02)$, indicating that workers of non-acute care wards are more prone to develop emotional exhaustion. In this step, all the main products

Table 2. Moderated hierarchical regressions to measure the main and interaction effects of job demands and skill discretion on emotional exhaustion

\begin{tabular}{|c|c|c|c|c|c|c|c|c|c|}
\hline \multirow[t]{2}{*}{ Variable } & \multicolumn{3}{|c|}{$\begin{array}{c}\text { Step 1 } \\
\left(\mathrm{R}^{2}=0.02\right)\end{array}$} & \multicolumn{3}{|c|}{$\begin{array}{c}\text { Step 2 } \\
\left(\mathrm{R}^{2}=0.319^{* * *}\right. \\
\left.\Delta \mathrm{R}^{2}=0.30^{* * *}\right)\end{array}$} & \multicolumn{3}{|c|}{$\begin{array}{c}\text { Step 3 } \\
\left(\mathrm{R}^{2}=0.358^{* * *}\right. \\
\left.\Delta \mathrm{R}^{2}=0.04^{* *}\right)\end{array}$} \\
\hline & $\beta$ & $\mathrm{t}$ & $\mathrm{p}$ & $\beta$ & $\mathrm{t}$ & $\mathrm{p}$ & $\beta$ & $\mathrm{t}$ & $\mathrm{p}$ \\
\hline Gender $(1$ = female $)$ & 0.09 & 1.45 & 0.15 & 0.05 & 0.89 & 0.37 & 0.04 & 0.77 & 0.44 \\
\hline Age & -0.06 & -0.48 & 0.63 & -0.15 & -1.54 & 0.12 & -0.15 & -1.54 & 0.12 \\
\hline $\begin{array}{l}\text { Marital status }(1=\text { married or living } \\
\text { with partner })\end{array}$ & 0.03 & 0.48 & 0.63 & 0.04 & 0.75 & 0.45 & 0.06 & 1.21 & 0.23 \\
\hline Type of unit (1 = acute care $)$ & -0.08 & -1.34 & 0.18 & -0.10 & -1.86 & 0.06 & -0.12 & -2.29 & 0.02 \\
\hline Job seniority & 0.03 & 0.28 & 0.78 & 0.20 & 2.09 & 0.04 & 0.19 & 1.99 & 0.05 \\
\hline Disproportiate expectations (DE) & & & & 0.29 & 5.03 & 0.00 & 0.29 & 5.09 & 0.00 \\
\hline Cognitive demands (CD) & & & & 0.16 & 2.47 & 0.01 & 0.18 & 2.85 & 0.00 \\
\hline Quantitative demands (QD) & & & & 0.25 & 4.10 & 0.00 & 0.28 & 4.64 & 0.00 \\
\hline Skill discretion (SD) & & & & -0.24 & -4.32 & 0.00 & -0.17 & -3.09 & 0.00 \\
\hline $\mathrm{DE} \times \mathrm{SD}$ & & & & & & & -0.13 & -2.15 & 0.03 \\
\hline $\mathrm{CD} \times \mathrm{SD}$ & & & & & & & 0.07 & 1.24 & 0.21 \\
\hline $\mathrm{QD} \times \mathrm{SD}$ & & & & & & & 0.22 & 3.36 & 0.00 \\
\hline
\end{tabular}

$\mathrm{R}^{2}$ - coefficient of determination; $\beta$ - standardized regression coefficient; $\mathrm{t}$-Student's t-test.

$* * 0.01 \leq \mathrm{p} \leq 0.001 ; * * \mathrm{p}=0.00$. 


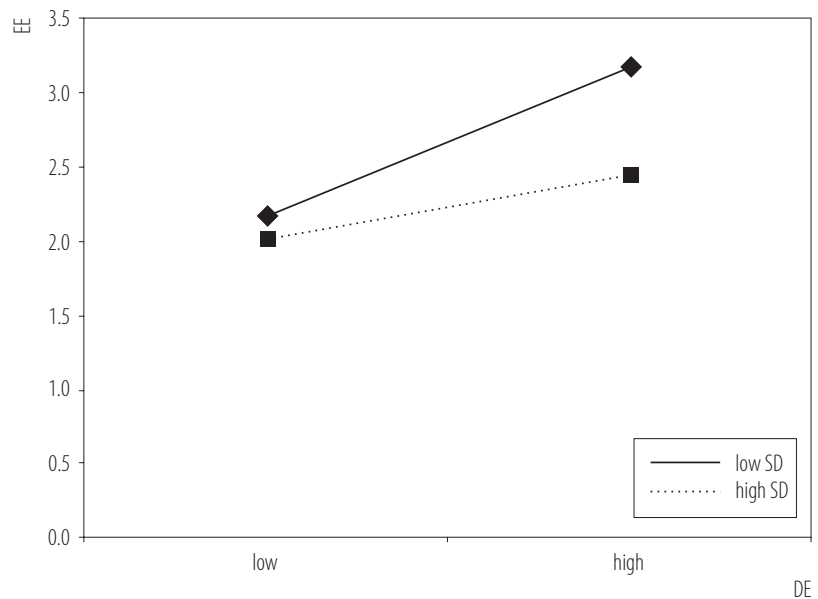

Fig. 1. Interaction between disproportionate patient expectations (DE) and skill discretion (SD) for emotional exhaustion (EE)

of job demands as well as skill discretion continued to be significant. As regards interactional terms, those that included disproportionate expectations $(\beta=-0.13, \mathrm{p}=0.03)$ and quantitative demands $(\beta=0.22, p=0.00)$, respectively, reported significant values, whereas the cross-products between cognitive demands and skill discretion did not.

The simple slope analysis (Figure 1) showed that when skill discretion was high (+1SD), disproportionate expectations were positively and significantly related to emotional exhaustion $(\beta=0.21, \mathrm{t}=2.51, \mathrm{p}=0.01)$. However, when skill discretion was low, the relationship was stronger $(\beta=0.49, \mathrm{t}=4.75, \mathrm{p}=0.00)$.

By contrast, the simple slope analysis (Figure 2) showed that when skill discretion was high, quantitative demands were more strongly associated with emotional exhaustion than in the case of low skill discretion.

At $+1 \mathrm{SD}, \beta$ reached the value of $0.56(\mathrm{t}=5.57, \mathrm{p}=0.00)$, whereas at $-1 \mathrm{SD}$ the relationship between quantitative demands and emotional exhaustion was not significant $(\beta=0.01, t=1.40, p=0.16)$.

Concerning disproportionate expectations, the results are in line with $\mathrm{H} 3 \mathrm{a}$ and suggest to reject $\mathrm{H} 3 \mathrm{~b}$. By contrast, for quantitative demands, even if the cross-product with

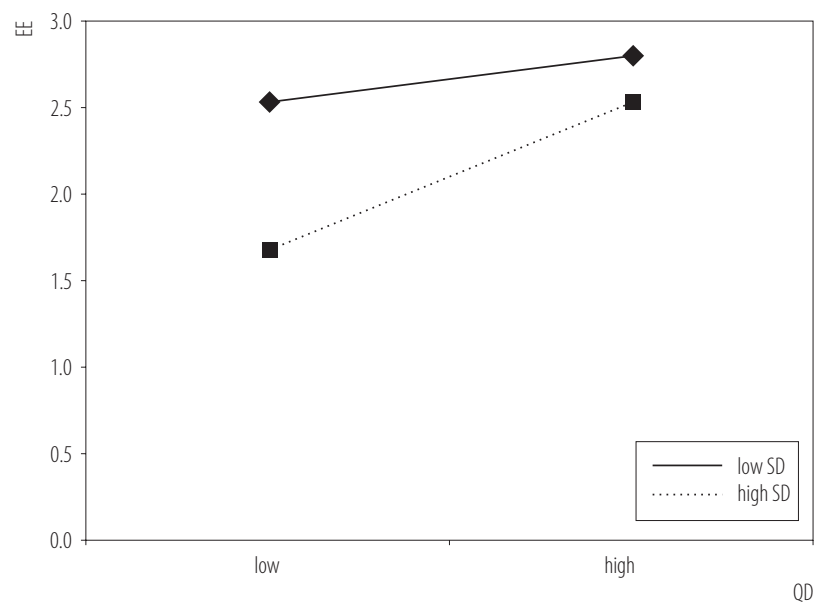

Fig. 2. Interaction between quantitative demands (QD) and skill discretion (SD) for emotional exhaustion (EE)

skill discretion was found to be significant, the pattern of the relationship would not completely reflect neither of the formulated hypotheses. Indeed, it shows a stronger relationship between quantitative demands and emotional exhaustion among those with high skill discretion as suggested by H3b. On the other hand, the plot showed the lowest level of emotional exhaustion among those with high skill discretion and low quantitative demands (as suggested by $\mathrm{H} 3 \mathrm{a}$ ), and an equal level of emotional exhaustion in conditions of high quantitative job demands among those with high and low skill discretion. Finally, as regards cognitive demands, both the alternative hypotheses, i.e., $\mathrm{H} 3 \mathrm{a}$ and $\mathrm{H} 3 \mathrm{~b}$ have to be rejected since the crossproduct was not found significant.

\section{Moderated regression with intention to leave as a dependent variable}

Table 3 reports the results of the moderated hierarchical regression where intention to leave was entered as a dependent variable.

In the case of the 1 st step, value of $\mathrm{R}^{2}$ was not significant. In the case of the 2 nd step, the model explained $16 \%$ of the variance. Within the control variables, only age $(\beta=-0.30$, 
Table 3. Moderated hierarchical regressions to measure the main and interaction effects of job demands and skill discretion on the intention to leave

\begin{tabular}{|c|c|c|c|c|c|c|c|c|c|}
\hline \multirow[t]{2}{*}{ Variable } & \multicolumn{3}{|c|}{$\begin{array}{c}\text { Step 1 } \\
\left(\mathrm{R}^{2}=0.02\right)\end{array}$} & \multicolumn{3}{|c|}{$\begin{array}{c}\text { Step 2 } \\
\left(\mathrm{R}^{2}=0.16^{* * * *}\right. \\
\left.\Delta \mathrm{R}^{2}=0.15^{* * *}\right)\end{array}$} & \multicolumn{3}{|c|}{$\begin{array}{c}\text { Step 3 } \\
\left(\mathrm{R}^{2}=0.21^{* * *},\right. \\
\left.\Delta \mathrm{R}^{2}=0.04^{* *}\right)\end{array}$} \\
\hline & $\beta$ & $\mathrm{t}$ & $\mathrm{p}$ & $\beta$ & $\mathrm{t}$ & $\mathrm{p}$ & $\beta$ & $\mathrm{t}$ & $\mathrm{p}$ \\
\hline Gender $(1$ = female $)$ & 0.05 & 0.82 & 0.41 & 0.03 & 0.53 & 0.59 & 0.02 & 0.40 & 0.68 \\
\hline Age & -0.21 & -1.83 & 0.07 & -0.30 & -2.79 & 0.00 & -0.30 & -2.83 & 0.00 \\
\hline $\begin{array}{l}\text { Marital status }(1=\text { married or living } \\
\text { with partner })\end{array}$ & 0.05 & 0.85 & 0.39 & 0.06 & 1.09 & 0.27 & 0.08 & 1.34 & 0.18 \\
\hline Type of unit (1 = acute care) & -0.03 & -0.55 & 0.58 & -0.00 & -0.12 & 0.90 & -0.01 & -0.21 & 0.83 \\
\hline Job seniority & 0.18 & 1.57 & 0.12 & 0.30 & 2.83 & 0.00 & 0.29 & 2.81 & 0.00 \\
\hline Disproportiate expectations (DE) & & & & 0.14 & 2.27 & 0.03 & 0.14 & 2.22 & 0.03 \\
\hline Cognitive demands (CD) & & & & 0.13 & 1.88 & 0.06 & 0.16 & 2.22 & 0.03 \\
\hline Quantitative demands (QD) & & & & 0.14 & 2.08 & 0.04 & 0.17 & 2.52 & 0.01 \\
\hline Skill discretion (SD) & & & & -0.31 & -5.18 & 0.00 & -0.27 & -4.31 & 0.00 \\
\hline $\mathrm{DE} \times \mathrm{SD}$ & & & & & & & -0.14 & -2.17 & 0.03 \\
\hline $\mathrm{CD} \times \mathrm{SD}$ & & & & & & & 0.18 & 2.93 & 0.00 \\
\hline $\mathrm{QD} \times \mathrm{SD}$ & & & & & & & 0.09 & 1.28 & 0.20 \\
\hline
\end{tabular}

Abbreviations as in Table 2.

$p=0.00)$ and job seniority $(\beta=0.30, p=0.00)$ were significant. Disproportionate expectations $(\beta=0.14, p=0.03)$, cognitive demands $(\beta=0.13, p=0.06)$ and quantitative demands $(\beta=0.14, \mathrm{p}=0.04)$ positively predicted intention to leave (H1 confirmed). In line with $\mathrm{H} 2 \mathrm{a}$ (H2b rejected), skill discretion was negatively associated with intention to leave $(\beta=-0.31, p=0.00)$.

In the case of the 3 rd step, entering the 3 interactional terms significantly increased the variance explained by the $\operatorname{model}\left(\Delta \mathrm{R}^{2}=0.04\right)$. All the main products continued to report significant $b$ values. Moreover, the cross-products between disproportionate expectations $(\beta=-0.14, p=0.03$ ) and skill discretion as well as those between cognitive demands and skill discretion $(\beta=0.18, \mathrm{p}=0.00)$ were significant. The cross-product involving quantitative demands was not significant. Figure 3 shows the patterns of the relationships between disproportionate expectations and intention to leave as a function of skill discretion.

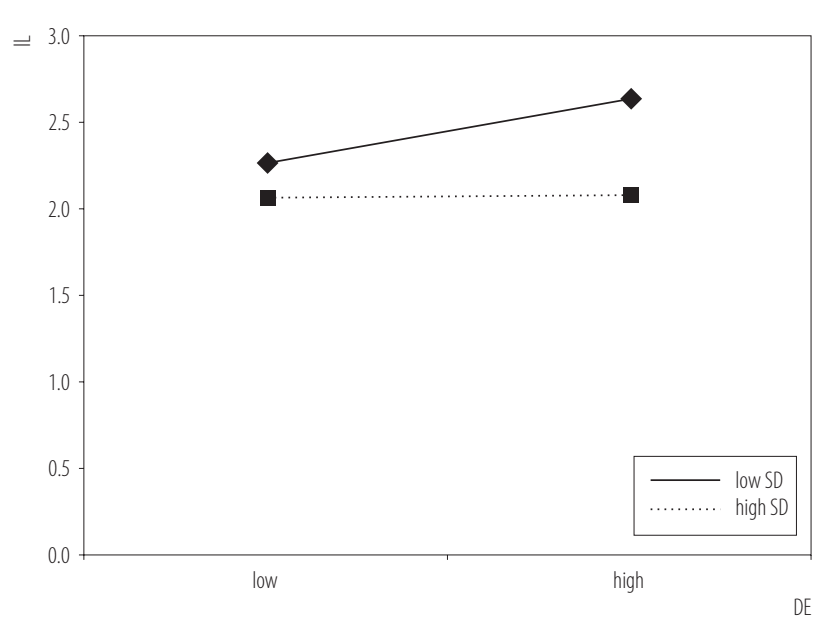

Fig. 3. Interaction between disproportionate patient expectations (DE) and skill discretion (SD) for the intention to leave (IL)

According to the slope test analyses, when skill discretion was high, the association between disproportionate expectations and intention to leave was not significant $(\beta=0.00, t=0.22, p=0.82)$. Whereas, in the case of low 


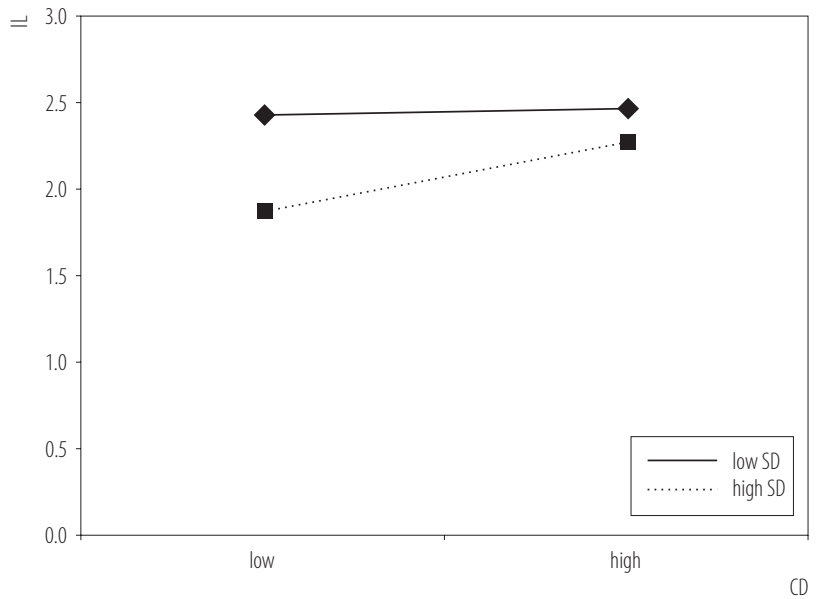

Fig. 4. Interaction between cognitive demands (DE) and skill discretion (SD) for the intention to leave (IL)

skill discretion, the association between disproportionate expectations and intention to leave was positive and significant $(\beta=0.18, t=5.85, p=0.00)$. Figure 4 shows the patterns of the relationships between cognitive demands and intention to leave as a function of skill discretion.

Slope test analyses indicated that the association between cognitive demands and intention to leave was weaker when skill discretion was low $(\beta=0.02, \mathrm{t}=0.45, \mathrm{p}=0.65)$, rather than when skill discretion was high $(\beta=0.20, t=4.47$, $\mathrm{p}=0.00)$.

Concerning disproportionate expectations, the results are in line with $\mathrm{H} 3 \mathrm{a}$ and suggest to reject $\mathrm{H} 3 \mathrm{~b}$. By contrast, for cognitive demands, even if the cross-product with skill discretion was found to be significant, the pattern of the relationship would not completely reflect neither of the formulated expectations. Indeed, it shows a stronger relationship between quantitative demands and emotional exhaustion among those with high skill discretion as suggested by H3b. On the other hand, the plot shows a lower level of intention to leave among those with higher skill discretion (as suggested by H3a). Finally, as regards quantitative demands, both the alternative hypotheses $\mathrm{H} 3 \mathrm{a}$ and $\mathrm{H} 3 \mathrm{~b}$ have to be rejected since the cross product was not found significant.

\section{Moderated regression with affective well-being}

\section{as a dependent variable}

Table 4 reports the results of the moderated hierarchical regression where affective well-being was entered as a dependent variable.

In the case of the 1 st step, the value of $\mathrm{R}^{2}$ was not significant.

In the case of the 2nd step, the model explained $18 \%$ of the variance. Within the control variables, only marital status was significant, indicating that workers living with partners showed significantly lower well-being at work than those who did not $(\beta=-0.27, p=0.00)$. Disproportionate expectations $(\beta=-0.23, \mathrm{p}=0.00)$ and quantitative demands $(\beta=-0.14, p=0.04)$ showed negative and significant associations with affective well-being, whereas cognitive demands were not significant (H1 partially not supported). In line with $\mathrm{H} 2 \mathrm{a}$ (H2b rejected), skill discretion showed a significant and positive relationship with affective well-being $(\beta=0.29, p=0.00)$.

In the case of the 3 rd step, and entering the 3 interaction effects, the $\mathrm{R}^{2}$ did not show a significant increment. However, the cross-product between disproportionate expectations and skill discretion was significant $(\beta=0.15, p=0.02)$.

Figure 5 illustrates the patterns of the relationships between disproportionate expectations and affective wellbeing as a function of skill discretion.

Accordingly with the slope test analyses, when skill discretion was high, the negative association between disproportionate expectations and affective well-being was not significant $(\beta=-0.06, t=-0.83, p=0.40)$. Whereas, in the case of low skill discretion, the association between disproportionate expectations and affective well-being was negative and significant $(\beta=-0.22, \mathrm{t}=-2.85, \mathrm{p}=0.00)$. These results are in line with $\mathrm{H} 3 \mathrm{a}$ and suggest to reject $\mathrm{H} 3 \mathrm{~b}$. Since the interactional terms of skill discretion with quantitative and cognitive demands were not significant, none of the 2 couples of alternative hypotheses (H11a/H11b) can be accepted. 
Table 4. Moderated hierarchical regressions to measure the main and interaction effects of job demands and skill discretion on the affective well-being

\begin{tabular}{|c|c|c|c|c|c|c|c|c|c|}
\hline \multirow[t]{2}{*}{ Variable } & \multicolumn{3}{|c|}{$\begin{array}{c}\text { Step } 1 \\
\left(\mathrm{R}^{2}=0.02\right)\end{array}$} & \multicolumn{3}{|c|}{$\begin{array}{c}\text { Step 2 } \\
\left(\mathrm{R}^{2}=0.18^{* * *}\right. \\
\left.\Delta \mathrm{R}^{2}=0.15^{* * *}\right)\end{array}$} & \multicolumn{3}{|c|}{$\begin{array}{c}\text { Step } 3 \\
\left(\mathrm{R}^{2}=0.19^{* * *}\right. \\
\left.\Delta \mathrm{R}^{2}=0.02\right)\end{array}$} \\
\hline & $\beta$ & $\mathrm{t}$ & $\mathrm{p}$ & $\beta$ & $\mathrm{t}$ & $\mathrm{p}$ & $\beta$ & $\mathrm{t}$ & $\mathrm{p}$ \\
\hline Gender (1 = female $)$ & 0.05 & 0.77 & 0.44 & 0.05 & 0.91 & 0.36 & 0.05 & 0.91 & 0.36 \\
\hline Age & 0.03 & 0.27 & 0.79 & 0.01 & 0.92 & 0.36 & 0.11 & 0.96 & 0.34 \\
\hline $\begin{array}{l}\text { Marital status }(1=\text { married or living } \\
\text { with partner })\end{array}$ & -0.10 & -1.54 & 0.12 & -0.10 & -1.75 & 0.08 & -0.11 & -2.01 & 0.04 \\
\hline Type of unit $(1=$ acute care $)$ & -0.03 & -0.44 & 0.66 & -0.07 & -1.15 & 0.25 & -0.07 & -1.19 & 0.23 \\
\hline Job seniority & 0.09 & 0.82 & 0.41 & -0.02 & -0.23 & 0.82 & -0.01 & -0.10 & 0.92 \\
\hline Disproportiate expectations (DE) & & & & -0.23 & -3.77 & 0.00 & -0.25 & -4.02 & 0.00 \\
\hline Cognitive demands (CD) & & & & -0.01 & -0.13 & 0.90 & -0.01 & -0.14 & 0.89 \\
\hline Quantitative demands (QD) & & & & -0.14 & -2.08 & 0.04 & -0.14 & -2.09 & 0.04 \\
\hline Skill discretion (SD) & & & & 0.29 & 4.86 & 0.00 & 0.28 & 4.51 & 0.00 \\
\hline $\mathrm{DE} \times \mathrm{SD}$ & & & & & & & 0.15 & 2.29 & 0.02 \\
\hline $\mathrm{CD} \times \mathrm{SD}$ & & & & & & & -0.01 & -0.11 & 0.91 \\
\hline $\mathrm{QD} \times \mathrm{SD}$ & & & & & & & -0.08 & -1.12 & 0.26 \\
\hline
\end{tabular}

Abbreviations as in Table 2.

\section{Moderated regression with job satisfaction as a dependent variable}

Table 5 reports the results of the moderated hierarchical regression where job satisfaction was entered as a dependent variable.

In the case of the 1 st step, the value of $\mathrm{R}^{2}$ was not significant.

In the case of the 2nd step, the model explained $29 \%$ of the variance. None of the control variables was significant. With respect to the main effects of job demands and skill discretion, all the terms were found significantly associated with job satisfaction.

In the case of the 3rd step, the model reported a significant increment of explained variance reaching a value of $\mathrm{R}^{2}$ equal to 0.32. Disproportionate expectations $(\beta=-0.27, p=0.00)$, quantitative demands $(\beta=-0.21$, $\mathrm{p}=0.00)$ and cognitive demands $(\beta=-0.21, \mathrm{p}=0.00)$ were negatively related to job satisfaction (H1 confirmed).

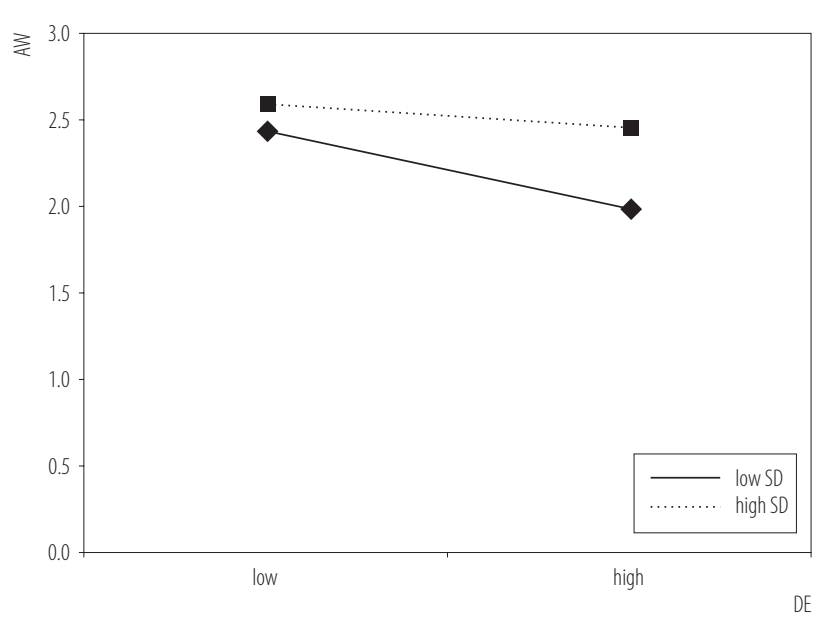

Fig. 5. Interaction between disproportionate patients expectations (DE) and skill discretion (SD) for the affective well-being (AW)

In line with $\mathrm{H} 2 \mathrm{a}$ (H2b rejected), skill discretion was positively related to job satisfaction $(\beta=0.35, \mathrm{p}=0.00)$. Moreover, the cross-product between disproportionate expectations and skill discretion $(\beta=0.13, p=0.04)$, as 
Table 5. Moderated hierarchical regressions to measure the main and interaction effects of job demands and skill discretion on job satisfaction

\begin{tabular}{|c|c|c|c|c|c|c|c|c|c|}
\hline \multirow[t]{2}{*}{ Variable } & \multicolumn{3}{|c|}{$\begin{array}{c}\text { Step 1 } \\
\left(\mathrm{R}^{2}=0.01\right)\end{array}$} & \multicolumn{3}{|c|}{$\begin{array}{c}\text { Step 2 } \\
\left(\mathrm{R}^{2}=0.29^{* * *}\right. \\
\left.\Delta \mathrm{R}^{2}=0.28^{* * *}\right)\end{array}$} & \multicolumn{3}{|c|}{$\begin{array}{c}\text { Step 3 } \\
\left(\mathrm{R}^{2}=0.32^{* * *},\right. \\
\left.\Delta \mathrm{R}^{2}=0.03^{* *}\right)\end{array}$} \\
\hline & $\beta$ & $\mathrm{t}$ & $\mathrm{p}$ & $\beta$ & $\mathrm{t}$ & p & $\beta$ & $\mathrm{t}$ & $\mathrm{p}$ \\
\hline Gender $(1$ = female $)$ & 0.05 & 0.82 & 0.41 & 0.07 & 1.31 & 0.19 & 0.07 & 1.46 & 0.14 \\
\hline Age & -0.13 & -1.13 & 0.26 & -0.02 & -0.26 & 0.82 & -0.02 & -0.23 & 0.82 \\
\hline $\begin{array}{l}\text { Marital status }(1=\text { married or living } \\
\text { with partner })\end{array}$ & -0.05 & -0.83 & 0.40 & -0.07 & -1.27 & 0.20 & -0.09 & -1.70 & 0.09 \\
\hline Type of unit ( 1 = acute care $)$ & 0.04 & 0.64 & 0.52 & -0.00 & -0.09 & 0.93 & 0.01 & 0.27 & 0.79 \\
\hline Job seniority & 0.11 & 0.95 & 0.34 & -0.06 & -0.58 & 0.56 & -0.04 & -0.45 & 0.65 \\
\hline Disproportionate expectations (DE) & & & & -0.27 & -4.58 & 0.00 & -0.27 & -4.60 & 0.00 \\
\hline Cognitive demands (CD) & & & & -0.08 & -1.29 & 0.20 & -0.11 & -1.72 & 0.09 \\
\hline Quantitative demands (QD) & & & & -0.19 & -2.98 & 0.00 & -0.21 & -3.43 & 0.00 \\
\hline Skill discretion (SD) & & & & 0.41 & 7.34 & 0.00 & 0.35 & 6.07 & 0.00 \\
\hline $\mathrm{DE} \times \mathrm{SD}$ & & & & & & & 0.13 & 2.07 & 0.04 \\
\hline $\mathrm{CD} \times \mathrm{SD}$ & & & & & & & -0.04 & -0.69 & 0.49 \\
\hline $\mathrm{QD} \times \mathrm{SD}$ & & & & & & & -0.21 & -3.17 & 0.00 \\
\hline
\end{tabular}

Abbreviations as in Table 2.

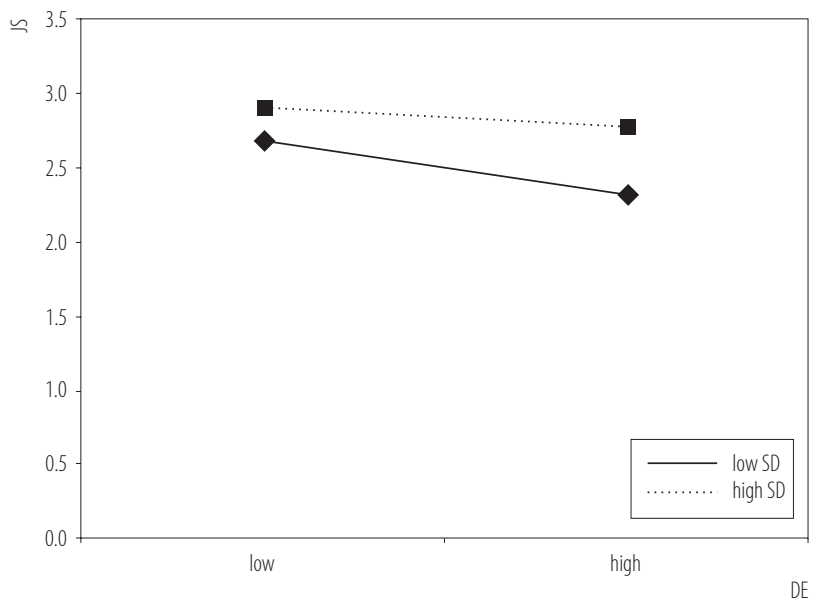

Fig. 6. Interaction between disproportionate patients expectations (DE) and skill discretion (SD) for job satisfaction (JS)

well as that between quantitative demands and skill discretion ( $\beta=-0.21, p=0.00$ ), was significant. The crossproduct between cognitive demands and skill discretion was not significant.
Figure 6 reports the plot of the relationships between disproportionate expectations and job satisfaction as a function of skill discretion.

In accordance with the slope test analyses, in the case of low skill discretion, the negative association between disproportionate expectations and job satisfaction was stron$\operatorname{ger}(\beta=-0.18, \mathrm{t}=-5.85, \mathrm{p}=0.00)$ if compared to the case of high skill discretion $(\beta=-0.20, \mathrm{t}=-2.18, \mathrm{p}=0.03)$.

Figure 7 reports the plot of the relationships between quantitative demands and job satisfaction as a function of skill discretion.

The slope test indicated that when skill discretion was low, the negative association between quantitative demands and job satisfaction was not significant $(\beta=-0.03$, $\mathrm{t}=-0.67, \mathrm{p}=0.50)$. Conversely, when skill discretion was high the negative relationship was significant $(\beta=-0.17$, $\mathrm{t}=-3.8, \mathrm{p}=0.00)$. These results are in line with H3a and suggest to reject $\mathrm{H} 3 \mathrm{~b}$. By contrast, for quantitative 


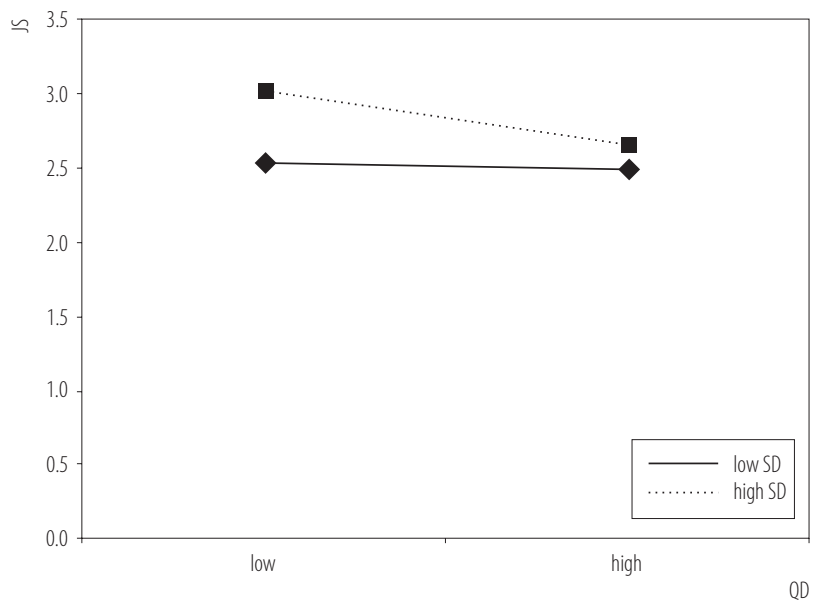

Fig. 7. Interaction between quantitative demands (QD) and skill discretion (SD) for job satisfaction (JS)

demands, even if the cross-product with skill discretion was found to be significant, the pattern of the relationship would not completely reflect neither of the formulated hypotheses. Indeed, it shows a stronger negative relationship between quantitative demands and job satisfaction among those with high skill discretion as suggested by H3b. On the other hand, the plot shows higher levels of emotional exhaustion among those with high skill discretion (as suggested by $\mathrm{H} 3 \mathrm{a}$ ). Finally, as regards cognitive demands, both the alternative hypotheses $\mathrm{H} 3 \mathrm{a}$ and $\mathrm{H} 3 \mathrm{~b}$ have to be rejected since the cross-product was not found significant.

\section{DISCUSSION}

The aim of the present study was to deepen the knowledge on the nature of a specific job characteristic, i.e., skill discretion. To accomplish this, both direct effect and interactive effect with regard to skill discretion were tested.

In addition to the main and interactional effects of skill discretion, the present study also made it possible to test the direct effect of job demands (i.e., disproportionate expectations, cognitive demands, and quantitative demands) on the workers' outcomes considered in the study (i.e., emotional exhaustion, intention to leave, affective well-being and job satisfaction).
Starting from the last point, disproportionate expectations and quantitative demands were found, as expected, to be significantly associated with emotional exhaustion, intention to leave, reduced affective well-being and job dissatisfaction. These results confirm the existing body of literature [4,5], corroborating the evidence, in line with the theory of Conservation of Resources [36,37] that suggests that job demands are associated with psychological costs because they require the use of acquired resources. Cognitive demands were the only exception. In the present study they emerged as a weak predictor of affective well-being. Indeed, although the univariate analyses showed significant associations between cognitive demands and the positive outcome, in the regression models, the significance disappeared after controlling for others job demands and skill discretion.

As regards the direct effects, in all cases, skill discretion worked as a resource, reducing emotional exhaustion and intention to leave, and, on the other hand, increasing job satisfaction and affective well-being. These results, in line with some studies in the previous literature [4,5,50], highlight the protective and motivational role of skill discretion, and are in contrast with those that suggest that skill discretion represents a risk factor in the workplace [54]. As regards the interactive effects, broadly speaking, the results indicate that in $33 \%$ of the combinations analyzed, skill discretion works as a buffer, by helping workers cope with high job demands as suggested by $\mathrm{H} 3 \mathrm{a}$.

In no case was the pattern suggested by H3b, which postulates the exacerbating effect of skill discretion, found. However, in $25 \%$ of the cases, the cross-product was found significant but showing an unexpected pattern in the middle between $\mathrm{H} 3 \mathrm{a}$ and $\mathrm{H} 3 \mathrm{~b}$. A typical example is the pattern represented in Figure 7 (but the same is true for Figures 2 and 3), in which job satisfaction was higher among those with higher levels of skill discretion (H3a), but the relationship between quantitative demands and job satisfaction was stronger in conditions of high skill discretion (as suggested by $\mathrm{H} 3 \mathrm{~b}$ ). 
These results seem to indicate that workers benefit from skill discretion only when demands remain low, and not when demands are high, simultaneously suggesting that skill discretion requires energy to be accomplished. Specifically, stronger relationship between job demands and psychological outcome among those with lower skill discretion, rather than among those with higher skill discretion, suggests that skill discretion is not a resource in a pure sense, but that it also has some characteristics of job demands. Indeed, the way in which skill discretion works is exactly the opposite to what is stated in the $3 \mathrm{rd}$ principle of the COR theory [36,37], i.e., people with greater resources are less vulnerable to resource loss and more capable of orchestrating resource gain.

In addition, as regards the interactive effect, another unexpected finding should be noted.

The way in which skill discretion modifies the relationship between job demands and any of the considered outcomes seems to be, most of all, affected by the kind of demands with which skill discretion is combined. The only case in which skill discretion worked as a buffer tout-court was in combination with disproportionate expectations, in determining any of the considered outcomes (that concern 33\% aforementioned). These results, in accordance with the buffing hypothesis $[4,5]$, seem to suggest that disproportionate expectations could activate a striving situation for the workers in which skill discretion becomes a salient resource, especially when these expectations are high. Among the considered demands, disproportionate expectations constitute the only demand that explicitly refers to the relationship with the users. Hence, it is plausible that the exercise of competences and skills aimed at fulfilling disproportionate expectations of patients may be perceived as challenging by nurses because of the opportunity to be rewarded and recognized by users for the high quality of their performance and/or service provided (over the expectations). This explanation is consistent with the recent studies that have found that gratitude and support from patients have a central importance in nursing well-being, i.e., showing a protective role against burnout $[65,66]$. Completely different from the case described above is the case in which skill discretion interacts with quantitative and cognitive demands.

Skill discretion does not moderate cognitive demands when job satisfaction, emotional exhaustion and affective well-being are dependent variables, and moderate intention to leave only in the case of low cognitive demands. Moreover, skill discretion does not moderate quantitative demands on affective well-being or intention to leave, but moderates emotional exhaustion and job satisfaction in the case of low cognitive demands.

As regards the relationship of quantitative and cognitive demands with the outcomes, the reasons why skill discretion works as a moderator in some cases but not in others are difficult to find. Indeed, since all the outcomes have prominently affective components, no specific differences in term of significance were expected when associated with the main effect and the cross-product involving the same job demands (e.g., cognitive demands versus all the outcomes considered). Moreover, the presence of the main and the interactive terms of disproportionate expectations in the models may have obscured the effect of other demands. In fact, disproportionate expectations is the only demand that contains an affective component, and it also shows the highest correlation with all the outcomes.

Further, it should be noted that skill discretion showed the highest negative correlation with cognitive demands, followed by quantitative demands. This statistical overlap between those 3 independent variables might have made it difficult to find the interactive effects.

Moreover, the statistical overlap suggests that those 3 aspects have something in common. It may be the cognitive demanding component of the job. As regards this, another consideration can occur using the "double match principle" in the Demand-Induced Stress 
Compensation (DISC) model by de Jonge et al. [67,68]. It states that the interactional effect of a job demand and a job resource is greater as the nature of the 2 elements involved is qualitatively similar. In the present study, skill discretion works in coherence with this principle but with a contrary mechanism.

Skill discretion, when interacts with those demands, qualitatively similar, does not moderate or moderates only when the demands are low. An explanation, that is in agreement with what was hypothesized in the present paper, is that it is so because they require a mobilization of the same kind of resources or personal energy. Indeed, skill discretion, cognitive demands, and, in some way, quantitative demands require cognitive resources. Learning new things may also conflict with quantitative demands because of insufficient time. Hence, skill discretion may moderate them at least in those conditions in which qualitatively similar job demands remain low.

Indeed, if job demands are overwhelming and do not leave resources necessary for the learning process, skill discretion rather than a resource may work as a form of additional demand, and contribute to the process of depletion of energy, altering psychological well-being of workers (e.g., performing more tasks that involve, simultaneously, high cognitive demands and high skill discretion).

This is also in coherence with the fact that skill discretion works as a buffer tout-court when affective/relational demands, such as disproportionate expectations, are involved. In this case, it is possible to assume that the 2 elements, as they have quite different qualitative natures, do not conflict because workers are drawn to different resources to accomplish them. In fact, correlations between disproportionate expectations and skill discretion also show a not significant association, indicating that the 2 aspects have little in common. On the contrary, in this situation, skill discretion works as a resource that helps manage the relationship with patients with unrealistic expectations towards the service and the care-providers.
Future studies may further deepen knowledge on this mechanism by developing a research program explicitly referring to the framework of the DISC model $[67,68]$. Moreover, future research should also be aimed at testing the role of skill discretion in combination with other job demands and job resources, in order to understand more clearly whether and when skill discretion may contribute to draining energy as well as whether and which other job resources may enhance learning process, also in stressful conditions.

Overall, these results suggest, in accordance with de Jonge and Dormann [10,53], that scales including specific rather than broad operationalizations of job demands and job resources should be preferred and help identify their specific effects on workers' health. Moreover, these results give some empirical basis to the argument that skill discretion may be a particular job characteristic, with a nature that places it between the concept of job demands and job resources. Indeed, referring to the theoretical framework of the COR theory [36,37], it is possible to state that it shows aspects that refer both to the gain process (i.e., acquisition of competence an opportunity to exercise them) and to the loss process (i.e., mobilization of energy and resources required to accomplish the learning process).

\section{Limitations of the study}

The present study has some limitations. One concern is that a non-randomized sampling procedure was used. In addition, the study focused only on 1 professional group. Both of these aspects can limit generalizability of the results. Another important limitation of this study is the fact that important characteristics, which the literature has recognized as relevant in the stress process, were not taken into consideration. Some examples are personal variables, social support, commitment and coping. Moreover, all of the measures employed were self-reported, and data came from a single source, which may introduce the issue of common method variance. Future studies may benefit 
from the employment of alternative research designs that include a combination of objective and subjective measures or use data from multiple sources (i.e., workers and supervisor).

Cross-sectional design of the study constitutes yet another important limitation. Therefore, caution in the interpretation of the results must be exercised. It is assumed that job demands and skill discretion are antecedents of emotional exhaustion, intention to leave, job satisfaction and wellbeing. However, the opposite could be also true. For example, elevated rates of emotional exhaustion could lead workers to develop negative attitudes towards jobs, workplace contexts and organizations. In the future, in order to test both directions of the relationship, a longitudinal study design should be employed.

\section{CONCLUSIONS}

From the present study, some practical implications can be drawn.

Organizations that invest in training and implementation of work processes that provide for workers' learning opportunities would have multiple gains. Promoting excellence and high level competences among workers, simultaneously fosters job satisfaction, psychological health and intention to stay. In this sense, job re-design aimed at increasing job variety, exchange programs across hospitals and wards, and mentoring programs are examples of interventions that can be implemented, and that can allow nurses to acquire new work experience and expand their skills.

At the same time, this study also suggests that skill discretion is not a resource in the pure sense but that it requires, by itself, a certain mobilization of energy. This has relevant implications for job design: job demand and skill discretion should be balanced carefully in order to promote job well-being and sustain worker retention. In fact, the study indicates that the healthier conditions are those that allow workers to spend as much energy as possible on learning and acquiring new skills. In over-demanding occupations, excessive workload can lead to sacrificing time or energy that could be used for acquiring new knowledge. As a consequence, emotional exhaustion and job dissatisfaction also increase.

\section{REFERENCES}

1. Karasek RA. Job demands, job decision latitude, and mental strain: Implications for job redesign. Adm Sci Q. 1979;24(2):285-308, http://dx.doi.org/10.2307/2392498.

2. Demerouti E, Bakker AB, Nachreiner F, Schaufeli WB. The job demands-resources model of burnout. J Appl Psychol.2001;86(3):499-512,http://dx.doi.org/10.1037/0021-9010. 86.3.499.

3. Bakker AB, Demerouti E. The Job Demands-Resources model: State of the art. J Manage Psychol. 2007;22(3):309-28, http://dx.doi.org/10.1108/02683940710733115.

4. Häusser JA, Mojzisch A, Niesel M, Schulz-Hardt S. Ten years on: A review of recent research on the Job Demand-Control (-Support) model and psychological wellbeing. Work Stress. 2010;24(1):1-35, http://dx.doi.org/10. 1080/02678371003683747.

5. Van der Doef M, Maes S. The job Demand-Control (-Support) Model and psychological well-being: A review of 20 years of empirical research. Work Stress. 1999;13(2):87-114, http:// dx.doi.org/10.1080/026783799296084.

6. Bakker AB, van Veldhoven M, Xanthopoulou D. Beyond the Demand-Control model: Thriving on high job demands and resources. J Pers Psychol. 2010;9(1):3-16, http://dx.doi. org/10.1027/1866-5888/a000006.

7. Dormann C, Zapf D. Social support, social stressors at work, and depressive symptoms: Testing for main and moderating effects with structural equations in a three-wave longitudinal study. J Appl Psychol. 1999;84(6):874-84, http://dx.doi. org/10.1037/0021-9010.84.6.874.

8. Kim H, Stoner M. Burnout and turnover intention among social workers: Effects of role stress, job autonomy and social support. Admin Soc Work. 2008;32(3):5-25, http://dx.doi. org/10.1080/03643100801922357. 
9. Viswesvaran C, Sanchez JI, Fisher J. The role of social support in the process of work stress: A meta-analysis. J Vocat Behav. 1999;54(2):314-34, http://dx.doi.org/10.1006/ jvbe.1998.1661.

10. De Jonge J, van Vegchel N, Shimazu A, Schaufeli W, Dormann C. A longitudinal test of the Demand-Control Model using specific job demands and specific job control. Int J Behav Med. 2010;17(2):125-33, http://dx.doi.org/10.1007/ s12529-010-9081-1.

11. Dollard MF, Winefield HR, Winefield AH, de Jonge J. Psychosocial job strain and productivity in human service workers: A test of the demand-control-support model. J Occup Organ Psychol. 2000;73(4):501-10, http://dx.doi. org/10.1348/096317900167182.

12. Van Ruysseveldt J, Proost K, Verboon P. The role of workhome interference and workplace learning in the energydepletion process. Manage Rev. 2011;22(2):151-68.

13. Grau-Alberola E, Gil-Monte PR, García-Juesas JA, Figueiredo-Ferraz $\mathrm{H}$. Incidence of burnout in Spanish nursing professionals: A longitudinal study. Int J Nurs Stud. 2010;47(8):1013-20, http://dx.doi.org/10.1016/j.jinur stu.2009.12.022.

14. McHugh MD, Kutney-Lee A, Cimiotti JP, Sloane DM, Aiken LH. Nurses' widespread job dissatisfaction, burnout, and frustration with health benefits signal problems for patient care. Health Aff. 2011;30(2):202-10, http://dx.doi. org/10.1377/hlthaff.2010.0100.

15. Hayes LJ, O'Brien-Pallas L, Duffield C, Shamian J, Buchan J, Hughes F, et al. Nurse turnover: A literature review - An update. Int J Nurs Stud. 2012;49(7):887-905, http://dx.doi.org/10.1016/j.jijnurstu.2011.10.001.

16. Martini M, Converso D. [Studying burnout in the Healthcare: Relationship with the patients and work-family connection as requests and resources]. G Ital Med Lav Ergon. 2012;34:A41-50. Italian.

17. Loera B, Gattino S, Converso D. [Organizational justice, social support and burnout among health-care workers: Direct and moderating effects]. Psicologia della
Salute. 2013;1:27-48, http://dx.doi.org/10.3280/PDS2013001002. Italian.

18. Greenglass ER, Burke RJ. Hospital downsizing, individual resources, and occupational stressors in nurses. Anxiety Stress Copin. 2000;13(4):371-90, http://dx.doi. org/10.1080/10615800008248342.

19. Organisation for Economic Co-operation and Development. Health at a Glance 2013: OECD Indicators. Paris: The Organisation; 2013, http://dx.doi.org/10.1787/health_glance2013-en.

20. Brunetto Y, Teo S. Retention, burnout and the future of nursing. J Adv Nurs. 2013;69(12):2772-3, http://dx.doi. org/10.1111/jan.12309.

21. Kirpal S. Work identities of nurses: Between caring and efficiency demands. Career Dev Int. 2004;9(3):274-304, http:// dx.doi.org/10.1108/13620430410535850.

22. Dormann C, Zapf D. Customer-related social stressors and burnout. J Occup Health Psychol. 2004;9(1):61-82, http:// dx.doi.org/10.1037/1076-8998.9.1.61.

23. Theorell T, Karasek RA. Current issues relating to psychosocial job strain and cardiovascular disease research. J Occup Health Psychol. 1996;1(1):9-26, http://dx.doi.org/ 10.1037/1076-8998.1.1.9.

24. Cordes CL, Dougherty TW. A review and integration of research on job burnout. Acad Manage Rev. 1993;18:621-56, http://dx.doi.org/10.1037/1076-8998.10.1.64.

25. Maslach C, Schaufeli WB, Leiter MP. Job burnout. Ann Rev Psychol. 2001;52(1):397-422, http://dx.doi.org/10.1146/ annurev.psych.52.1.397.

26. Loera B, Converso D, Viotti S. Evaluating the psychometric properties of the Maslach Burnout Inventory-Human Services Survey (MBI-HSS) among Italian nurses: How many factors must a researcher consider? PLoS One. 2014;9(12):e114987, http://dx.doi.org/10.1371/journal. pone. 0114987.

27. McCarthy G, Tyrrell MP, Lehane E. Intention to 'leave' or 'stay' in nursing. J Nurs Manage. 2007;15(3):248-55, http:// dx.doi.org/10.1111/j.1365-2834.2007.00648.x. 
28. Van Breukelen W, van der Vlist R, Steensma H. Voluntary employee turnover: Combining variables from the traditional' turnover literature with the theory of planned behavior. J Organ Behav. 2004;25(7):893-914, http://dx.doi. $\operatorname{org} / 10.1002 /$ job.281.

29. Simoens S, Villeneuve M, Hurst J. Tackling nurse shortages in OECD countries. Paris: OECD Publishing, OECD health working papers No. 19, 2005 [cited 2015 Nov 5]. Available from: http:/www.oecd.org/health/health-systems/ 34571365.pdf.

30. Diener E. Subjective well-being. Psychol Bull. 1984; 95(3):542-75, http://dx.doi.org/10.1037/0033-2909.95.3.542.

31. Diener E. Subjective well-being: The science of happiness and a proposal for a national index. Am Psychol. 2000;55(1):34-43, http://dx.doi.org/10.1037/0003-066X. 55.1.34.

32. Van Horn JE, Taris TW, Schaufeli WB, Schreurs PJG. The structure of occupational well-being: A study among Dutch teachers. J Occup Organ Psychol. 2004;77(3):365-75, http://dx.doi.org/10.1348/0963179041752718.

33. Danna K, Griffin RW. Health and well-being in the workplace: A review and synthesis of the literature. J Manage. 1999;25(3):357-84, http://dx.doi.org/10.1177/0149206 39902500305.

34. Cranny CL, Smith PS, Stone E. Job satisfaction: How people feel about their job and how it affects their performance. New York: Lexington Books; 1992.

35. Wanous JP, Reichers AE, Hudy MJ. Overall job satisfaction: How good are single-item measures? J Appl Psychol. 1997;82(2):247-52, http://dx.doi.org/10.1037/0021-90 10.82.2.247.

36. Hobfoll SE. The influence of culture, community, and the nested-self in the stress process: Advancing conservation of resources theory. Appl Psychol. 2001;50(3):337-421, http://dx.doi.org/10.1111/1464-0597.00062.

37. Westman M, Hobfoll SE, Chen S, Davidson OB, Laski S. Organizational stress through the lens of Conservation of Resources (COR) theory. In: Pamela L, Perrewe PL,
Ganster DC, editors. Research in occupational stress and well-being (Vol. 4): Exploring interpersonal dynamics. London: Emerald Group Publishing Limited; 2004, p. 167-220, http://dx.doi.org/10.1016/S1479-3555(04)04005-3.

38. Hobfoll SE, Freddy J. Conservation of resources: A general stress theory applied to burnout. In: Schaufeli WB, Maslach C, Marek T, editors. Professional burnout: Recent development in theory and research. London: Taylor \& Francis; 1993, p. 129-55.

39. Panari C, Guglielmi D, Simbula S, Depolo M. Can an opportunity to learn at work reduce stress? A revisitation of the job demand-control model. JWL. 2010;22(3):166-79, http://dx.doi.org/10.1108/13665621011028611.

40. Viotti S, Converso D, Loera B. [Job satisfaction, job burnout and their relationships with work' and patients' characteristics: A comparison between intensive care units (ICU) and not-intensive care units (not-ICU)]. G Ital Med Lav Ergon. 2012;34:B52-60. Italian.

41. Lee RT, Ashforth BE. A meta-analytic examination of the correlates of the three dimensions of job burnout. J Appl Psychol. 1996;81(2):123-33, http://dx.doi.org/10. 1037/0021-9010.81.2.123.

42. Van Daalen G, Willemsen TM, Sanders K, van Veldhoven MJPM. Emotional exhaustion and mental health problems among employees doing "people work": The impact of job demands, job resources and family-to-work conflict. Int Arch Occup Environ Health. 2009;82(3):291-303, http://dx.doi.org/10.1007/s00420-008-0334-0.

43. Greenglass ER, Burke RJ, Fiksenbaum L. Workload and burnout in nurses. J Community Appl Soc. 2001;11(3): 211-15, http://dx.doi.org/10.1002/casp.614.

44. Borritz M, Bültmann U, Rugulies R, Christensen KB, Villadsen E, Kristensen TS. Psychosocial work characteristics as predictors for burnout: Findings from 3-year follow up of the PUMA Study. J Occup Environ Med. 2005;47(10):101525, http://dx.doi.org/10.1097/01.jom.0000175155.50789.98.

45. Crawford ER, Le Pine JA, Rich BL. Linking job demands and resources to employee engagement and burnout: 
A theoretical extension and meta-analytic test. J Appl Psychol. 2010;95(5):834-48, http://dx.doi.org/10.1037/a0019364.

46. Nahrgang JD, Morgeson FP, Hofmann DA. Safety at work: A meta-analytic investigation of the link between job demands, job resources, burnout, engagement, and safety outcomes. J Appl Psychol. 2011;96(1):71-94, http://dx.doi. org/10.1037/a0021484.

47. Hayes LJ, O’Brien-Pallas L, Duffield C, Shamian J, Buchan J, Hughes F, et al. Nurse turnover: A literature review - An update. Int J Nurs Stud. 2012;49(7):887-905, http://dx.doi.org/10.1016/j.jnurstu.2011.10.001.

48. Takase M, Oba K, Yamashita N. Generational differences in factors influencing job turnover among Japanese nurses: An exploratory comparative design. Int J Nurs Stud. 2009;46(7):957-67, http://dx.doi.org/10.1016/j.ijnurstu. 2007.10.013.

49. Li J, Fu H, Hu Y, Shang L, Wu Y, Kristensen TS, et al. Psychosocial work environment and intention to leave the nursing profession: Results from the longitudinal Chinese NEXT study. Scand J Public Health. 2010;38(3): 69-80, http://dx.doi.org/10.1177/1403494809354361.

50. Rafferty Y, Friend R, Landsbergis PA. The association between job skill discretion, decision authority and burnout. Work Stress. 2001;15(1):73-85, http://dx.doi. org/10.1080/02678370120791.

51. Shalley CE, Gilson LL, Blum TC. Matching creativity requirements and the work environment: Effects on satisfaction and intentions to leave. Acad Manage J. 2000;43(2): 215-23, http://dx.doi.org/10.2307/1556378.

52. Proost K, van Ruysseveldt J, van Dijke M. Coping with unmet expectations: Learning opportunities as a buffer against emotional exhaustion and turnover intentions. Eur J Work Organ Psychol. 2012;21(1):7-27, http://dx.doi.org/10.1080/ 1359432X.2010.526304.

53. De Jonge J, Reuvers MM, Houtman IL, Bongers PM, Kompier MAJ. Linear and nonlinear relations between psychosocial job characteristics, subjective outcomes, and sickness absence: Baseline results from SMASH. J Occup Health
Psychol. 2000;5(2):256-68, http://dx.doi.org/10.1037/10768998.5.2.256.

54. Bakker AB, Demerouti E, Euwema MC. Job resources buffer the impact of job demands on burnout. J Occup Health Psychol. 2005;10(2):170-80, http://dx.doi.org/10.1037/10768998.10.2.170.

55. Karasek RA. Job content instrument questionnaire and user's guide, Version 1.1. Lowell: University of Massachusetts; 1985.

56. Baldasseroni A, Camerino D, Cenni P, Cesana GC, Fattorini E, Ferrario M, et al. [The assessment of psychosocial risk factors: The Italian version of the Job Content Questionnaire by R.A. Karasek]. Fogli di Informazione Ispesl. 2001, [cited 2014 Oct 20]; 14(3):20-32. Available from: http://www. ispesl.it/informazione/Karasek.htm. Italian.

57. Maslach C, Jackson SE. Maslach burnout inventory. 2nd ed. Palo Alto: Consulting Psychologists Press; 1986.

58. Daniels K, Brough P, Guppy A, Peters-Bean KM, Weatherstone L. A note on modification to Warr's measures of affective well-being at work. J Occup Organ Psychol. 1997;70:129-38, http://dx.doi.org/10.1111/j.2044-8325.1997. tb00638.x.

59. Dolbier CL, Webster JA, McCalister KT, Mallon MW, Steinhardt MA. Reliability and validity of a single-item measure of job satisfaction. Am J Health Promot. 2005;19(3): 194-8, http://dx.doi.org/10.4278/0890-1171-19.3.194.

60. Tummers GER, van Merode GG, Landeweerd JA. The diversity of work: Differences, similarities and relationships concerning characteristics of the organization, the work and psychological work reactions in intensive care and non-intensive care nursing. Int J Nurs Stud. 2002;39:841-55, http:// dx.doi.org/10.1016/S0020-7489(02)00020-2.

61. Wilks DC, Neto F. Workplace well-being, gender and age: Examining the 'double jeopardy' effect. Soc Ind Res. 2013;114(3):875-90, http://dx.doi.org/10.1007/s11205012-0177-7.

62. Kirkcaldy BD, Martin T. Job stress and satisfaction among nurses: Individual differences. Stress Health. 
2000;16(2):77-89, http://dx.doi.org/10.1002/(SICI)1099-1700 (200003)16:2.

63. Aiken LS, West SG. Multiple regression: Testing and interpreting interactions. Newbury Park (CA): Sage; 1991.

64. Field A. Discover Statistics using SPSS. 3th ed. London: Sage; 2009.

65. Converso D, Loera B, Viotti S, Martini M. Do positive relations with patients play a protective role for healthcare employees? Effects of patients' gratitude and support on nurses' burnout. Front Psychol. 2015;6:470, http://dx.doi. org/10.3389/fpsyg.2015.00470.

66. Martini M, Converso D. Gratitude, or the positive side of the relationship with patients. Development and first validation of new instruments: A scale of gratitude perceived by operators and a scale of support offered by the gratitude expressed by their patients. Psychol. 2014;5:572-80, http:// dx.doi.org/10.4236/psych.2014.56067.

67. De Jonge J, Dormann C. The DISC model: Demand-Induced Strain Compensation mechanisms in job stress. In: Dollard MF, Winefield AH, Winefield HR, editors. Occupational stress in the service professions. London: Taylor \& Francis; 2003, p. 43-74.

68. De Jonge J, Dormann C, van den Tooren M. The DemandInduced Strain Compensation model: Renewed theoretical considerations and empirical evidence. In: Näswall K, Hellgren J, Sverke M, editors. The individual in the changing working life. Oxford: Cambridge University Press; 2008, p. 67-87.

This work is available in Open Access model and licensed under a Creative Commons Attribution-NonCommercial 3.0 Poland License - http://creativecommons.org/ licenses/by-nc/3.0/pl/deed.en. 